\title{
Effect of Hyperlipidemia on Cell Mediated Immunity; Could it be as Predisposing Factor of Cancer Risk
}

\author{
Zeinab Emruzi ${ }^{1}$, Pegah Babaheidarian ${ }^{2}$, Mahmoud Arshad $^{3}$ and Ghasem Ahangari*1 \\ ${ }^{1}$ Department of Medical Genetics, National Institute of Genetic Engineering and Biotechnology (NIGEB), Iran \\ ${ }^{2}$ Department of Pathology, Rasoul Akram Hospital, Iran
}

${ }^{3}$ Department of Endocrinology, Rasoul Akram Hospital, Iran

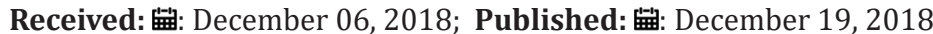

*Corresponding author: Ghasem Ahangari, Department of Medical Genetics, National Institute of Genetic Engineering and Biotechnology (NIGEB), Iran

\begin{abstract}
Background: The relationship between obesity and some diseases proposes a main interaction among the host lipid metabolism and immune system. On the other hand, inflammation and remarkably cytokines play a key role in defense against pathogenesis and tumor initiation.

Objective: In this project, we aim to investigate the effects of hyperlipidemia on Th1 differentiation, expression of Th1 secreted cytokines and the risk of cancer.

Methods: PBMCs were isolated from whole blood of 40 hyperlipidemia patients and 40 normal volunteers. After synthesizing cDNAs from total mRNAs, real-time PCR was performed for IL-2, IFN- $\gamma$, TNF- $\alpha$ cytokines, T-bet transcription factor and $\beta$-actin (as an internal control). The expression ratios were analyzed in hyperlipidemia patients in comparison with the normal group.

Results: statistically significant decrease was shown at the mRNA expression level of IL-2, IFN- $\gamma$, TNF- $\alpha$ and T-bet genes in hyperlipidemia patients $(\mathrm{P} \leq 0.006)$.

Conclusion: High level cholesterol and LDL leads to decreased expression of Th1 related cytokines, weakened cell mediated immunity and increase risk of cancer in hyperlipidemia patients.
\end{abstract}

Keywords: Cancer; Cytokines; Hyperlipidemia; Inflammation

\section{Introduction}

Hyperlipidemia, increased serum cholesterol and triglycerides, as a metabolic disease results from impaired lipid metabolism by excessive intake of cholesterol or genetic deficiency. High blood cholesterol levels are caused by kidney diseases, diabetes, medication side effects, hypothyroidism, metabolic syndrome, polycystic ovary syndrome (PCOS) and Cushing's syndrome $[1,2]$. Hyperlipidemia not only causes the progress of atherosclerosis primarily as a result of increased serum cholesterol levels, but also leads to systemic inflammation that can be effective on disease development [3-5]. A variety of studies reported the effects of dietary fats on diseases such as age-related memory loss [6], infertility and endometriosis $[7,8]$ multiple sclerosis, breast cancer, prostate cancer, colon cancer and non-Hodgkin's lymphoma [914]. The immune system is a complex array of organs, tissues and specialized cells that protects us from outside invaders and tumor initiation in body. Studies to determine which metabolic disorder or combination of disorders in obese people increases their cancer risk have been inconclusive [15]. High level serum lipids lead to altered rates of cholesterol in the cell membrane and cytoplasm of macrophages. Therefore, hyperlipidemia might inhibit innate immune responses, cytokines release and inflammatory response and impair proper immune response to bacterial challenge [16] and increase risk of cancer $[17,18]$. On the other hand, in vitro studies show an increase in the number of IL-4 producing Th2 cells [19] and a decrease in Th1 response and cell immunity in ApoE-/mice [20-22].

By the measurement of cholesterol levels in patients with superficial esophageal cancer, Akihiro Sako et al. suggests that high levels of serum lipid might provide suitable conditions for the progress of lymph node metastasis in the early stage of esophageal 
cancer [23]. In contrast, some previous studies demonstrate low serum levels of cholesterol and triglycerides (TG) could lead to cancer morbidity $[24,25]$. Although all the studies about the effects of hyperlipidemia on immune response were dispersed, its relation to cancer is still controversial. We hypothesized that hyperlipidemia could reduce Th1 related cytokines and increased risk of cancer in human. For considering this purpose we decided to investigate the effect of high level of cholesterol and LDL on cell mediated immunity and expression of Th1 related cytokines in human.

Table 1: Demographic and clinical characteristics of samples.

\section{Materials and Methods}

\section{Study Population}

Forty untreated hypercholesterolemia patients in the clinic department of Hazrat Rasoul hospital and forty healthy individuals joined this study. The diagnosis of hypercholesterolemia was based upon an appropriate clinical history and measurement of LDL rate per weight. They all gave written informed consent, and the local ethics committee approved the study protocol.

\begin{tabular}{|c|c|c|c|c|c|c|c|c|}
\hline Groups & $\begin{array}{c}\text { Sample } \\
\text { Number }\end{array}$ & Weigh (Kg) & Age & Male/ Female & $\begin{array}{c}\text { Cholesterol } \\
(\mathbf{m g} / \mathbf{d l})\end{array}$ & LDL* $\left.^{*} \mathbf{m g} / \mathbf{d l}\right)$ & HDL $^{* *}(\mathbf{m g} / \mathbf{d l})$ & Triglyceride (mg/dl) \\
\hline Control & 40 & $75 \pm 14$ & $47 \pm 10$ & $18 / 22$ & $160.2 \pm 11$ & $102.2 \pm 11.8$ & $40.2 \pm 4.3$ & $129.8 \pm 15.8$ \\
\hline Patients & 40 & $85 \pm 13$ & $49 \pm 7$ & $19 / 21$ & $300.4 \pm 15$ & $158.8 \pm 14.5$ & $43.5 \pm 10.3$ & $124.1 \pm 30$ \\
\hline
\end{tabular}

Note: (“Low Density Lipoprotein, ${ }^{* *}$ High Density Lipoproteins)

\section{Inclusion and Exclusion Criteria}

The patients who smoked or had other current inflammatory, infectious diseases or neurological disorder, cardiovascular, diabetes and allergic diseases were excluded from the study. The control group were healthy individuals and they had no other hyperlipidemia diseases (Table 1).

\section{PBMC Isolation}

We collected $4 \mathrm{ml}$ of peripheral blood samples from the cubital vein of two study groups of normal controls and patients in EDTA-containing tubes. Then, peripheral blood mononuclear cells (PBMCs) were separated from total blood samples based on gradient density centrifugation technique by Ficoll hypaque (Pharmacia, Uppsula, Sweden).

\section{RNA Isolation and cDNA Synthesis}

The total cellular RNA was extracted from PBMC by High Pure RNA Isolation Kit (Roche, Germany) according to the manufacturer's instructions. To normalize RNA concentration, we measured its absorbance by using the Nano Drop 2000 instrument (Wilmington, USA) at $260 \mathrm{~nm}$. The RNA (400ng/ $\mu \mathrm{l})$ from each sample was used to synthesize the first-strand cDNA by the cDNA synthesis kit (Fermentase, Germany). Similarly, cDNA synthesis was carried out based on the manufacture's protocols. Ultimately, the cDNA samples were kept at $-70 \mathrm{oC}$ until we used them for PCR.

\section{PCR and Real-Time PCR Analyses}

Primers were designed using oligo7 software (WWW.oligo. net). To exclude amplification of genomic DNA and pseudo genes we confirmed the validity of the primers by blasting: http://www. ncbi.nlm.nih.gov/tools/primer-blast/ (Table 2). A common PCR technique was carried out for all samples in a final volume of $20 \mu \mathrm{l}$ with master mix PCR (Cinnagen, Tehran, Iran). Then the samples were loaded on a $1.5 \%$ gel. Real-time-PCR was performed with SYBR $®$ Green fluorescent dye (Light Cycler Fast Start DNA Master Plus SYBR Green I, Roche, Germany) to scan cDNA amplification by binding only to double stranded DNA and its fluorescent intensity was identified by Rotor gene (Termocicler Rotor-Gene ${ }^{\mathrm{TM}} 6000$ Corbett Research/ Australia). The melting curve analysis showed only one peak for each reaction and this was also confirmed by electrophoresis of PCR products that showed only one band of the expected size.

Table 2: Primers used in Real-Time PCR.

\begin{tabular}{|c|c|c|c|c|}
\hline Gene & Oligo Name & Primers Sequence & size & Accession Number \\
\hline \multirow{2}{*}{ IL-2 } & IL-2- F & ATTACAAGAATCCCAAACTCACCAG & \multirow{2}{*}{$217 \mathrm{bp}$} & NM_000586 \\
\hline & IL-2- R & GTTGTTTCAGATCCCTTTAGTTCC & & \\
\hline \multirow{2}{*}{ IFN- $\gamma$} & IFN- $\gamma-$ F & CGGTAACTGACTTGAATGTCCAAC & \multirow{2}{*}{$141 \mathrm{bp}$} & NM_000619 \\
\hline & IFN- $\gamma-\mathrm{R}$ & ACCATTACTGGGATGCTCTTCGAC & & \\
\hline \multirow{2}{*}{ TNF- $\alpha$} & TNF- $\alpha-F$ & СТССТTCAGACAСССТСАAСС & \multirow{2}{*}{$101 \mathrm{bp}$} & NMᄀ_000594 \\
\hline & TNF- $\alpha-\mathrm{R}$ & CGAAGTGGTGGTCTTGTTGC & & \\
\hline \multirow{2}{*}{ T-bet } & T-bet- F & CCAAGTTTAATCAGCACCAGACAG & \multirow{2}{*}{$131 \mathrm{bp}$} & NM_013351 \\
\hline & T-bet- $\mathrm{R}$ & CAAGACCACGTCCACAAACATCC & & \\
\hline \multirow{2}{*}{$\beta$ - actin } & $\beta$-actin- $F$ & AGACGCAGGATGGCATGGG & \multirow{2}{*}{$161 \mathrm{bp}$} & NM_001101 \\
\hline & $\beta$-actin- R & GAGACCTTCAACACCCCAGCC & & \\
\hline
\end{tabular}




\section{Statistical Analysis}

Data output from LinReg PCR software such as Cycle of threshold (Ct) and efficiency of each reaction were imported to Relative Expression Software Tool 2009 version (REST 2009).

\section{Results}

This study was performed on 40 untreated hyperlipidemia patients and 40 healthy people. It was important which hyperlipidemia patients have high level of cholesterol and LDL only while HDL and triglycerides level have to be normal. We investigated the effect of high level of cholesterol and LDL on T cell differentiation and cell mediated immunity.

\section{Electrophoresis of PCR Products}

The electrophoresis of PCR products associated to the studied genes showed specific sharp bands for IFN- $\gamma$ (141 bp), TNF- $\alpha$ (101 bp), T-bet (131 bp), IL-2 (217 bp) and $\beta$-actin (161 bp), without any primer dimers (Figure 1).

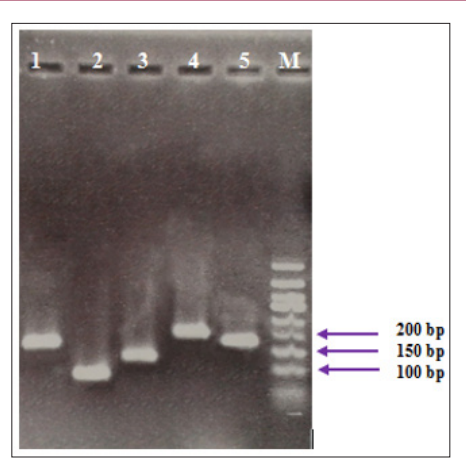

Figure 1: PCR products of studied genes on gel electrophoresis. The bands were related to 1: IFN-ץ (141 bp), 2: TNF-a (101 bp), 3: T-bet (131 bp), 4: IL-2 (217 bp), 5: $\beta$-actin (161 bp) and M: DNA ladder respectively.

\section{Hypercholesterolemia Decrease mRNA Expression of Th1 Related Cytokines}

In order to investigate the effect of Hypercholesterolemia on Th1 related cytokines, the mRNA expression levels of IL-2, IFN- $\gamma$ and TNF- $\alpha$ cytokines were measured by real time PCR. As reference gene for loading we used the housekeeping gene $\beta$-actin. The results showed a significantly decrease in mRNA expression of IL-2, IFN- $\gamma$ and TNF- $\alpha$ cytokines by $0.056,0.310$ and 0.285 respectively. The differences of cytokines and transcription factor of the patients group in compared with healthy individuals were statistically significant $(\mathrm{P} \leq 0.006)$ (Table 3$)$ and (Figure 2).

\section{Hypercholesterolemia Decrease mRNA Expression of Th1 Related Transcription Factor}

T-bet is an important transcription factor to differentiation of Th0 to Th1 and regulated expression of Th1 related cytokines. In order to investigate the effect of Hypercholesterolemia on Th1 differentiation, the mRNA expression levels of T-bet transcription factor were measured by real time PCR and $\beta$-actin housekeeping gene was used as reference gene. The result showed that Hypercholesterolemia lead to down regulated mRNA expression of T-bet transcription factor by 0.439 . The differences of the two groups were statistically significant $(\mathrm{P} \leq 0.006)$ (Table 3 ) and (Figure 2).

Table 3: Expression ratio of $\mathrm{T}$ cell differentiation related genes in hyperlipidemia patients.

\begin{tabular}{|c|c|c|c|c|c|}
\hline Gene & Type & $\begin{array}{c}\text { Reaction } \\
\text { Efficiency }\end{array}$ & Expression & P Value & Result \\
\hline B-actin & REF & 0.9047 & 1.000 & & \\
\hline IFN- $\gamma$ & TRG & 0.966 & 0.310 & 0.000 & DOWN \\
\hline TNF- $\alpha$ & TRG & 1.0279 & 0.285 & 0.000 & DOWN \\
\hline T-bet & TRG & 0.931 & 0.439 & 0.006 & DOWN \\
\hline IL-2 & TRG & 1.009 & 0.056 & 0.000 & DOWN \\
\hline
\end{tabular}

Note: (TRG-Target, REF-Reference).

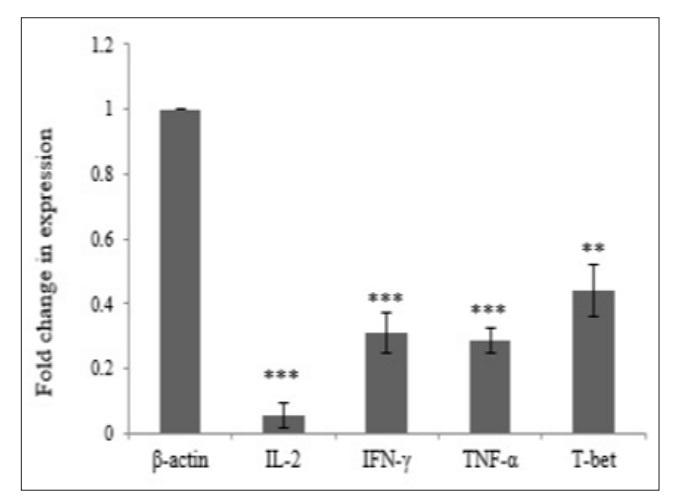

Figure 2: Th1 differentiation in hyperlipidemia patients. Expression of IFN- $\gamma$, TNF- $\alpha$, IL-2 cytokines and T-bet transcription factor decreased significantly $(\mathrm{P} \leq 0.006)$.

\section{Discussion}

Dyslipidemia, in particular high cholesterol and hyperlipidemia, is considered as an important metabolic disease throughout the world that is significantly associated with inflammation [26,27]. Hyperlipidemia begins partial inflammation by change of leukocyte activity and disrupting cytokine regulation, which worsens over time. Many studies have reported the effects of hyperlipidemia and dietary fats on immune responses, however, many of them have been carried out on animal models with focus on innate immunity. A deeper understanding of hyperlipidemia effects on the immune system will provide a more comprehensive investigation of the health risks of hyperlipidemia and risk of infectious diseases and cancer. In order to get an understanding of hyperlipidemia on the cell mediated immunity, we investigated the effect of high level of cholesterol and LDL on the Th1 cell differentiation. Many studies have reported weakened immune defense for ApoE-/- hypercholesterolemic mice against Candida albicans, Listeria monocytogenes, Klebsiella pneumonia and lymphocytic choriomeningitis virus (LCMV) infection [28-31].

In 1998 and 2009, Zhou X et al. reported that hypercholesterolemic mice shift the $\mathrm{T}$ lymphocyte response towards Th2 and the percentage of IL-4- versus IFN- $\gamma$-producing cells in the spleen augmented with enhancing levels of cholesterol 
$[20,22]$. Narasimha Rao et al. and other researchers showed that high level of LDL cholesterol leads to an increase of IL17 secreting CD4 cells and decrease of regulatory T cells in the spleen, but has no effects on IFN- $\gamma$ secreting CD4 cells [32]. Mailer RK et al. reported that increased TCR signaling in high-cholesterol dieted mice did not change the expression of activation markers or differentiation of $\mathrm{T}$ cell subsets except for Treg cells [33]. Similar results were reported by other researchers [34-36]. Jonathan D. Proto in 2018 demonstrated that reasonably high plasma cholesterol can disturb human T cell homeostasis invivo [37]. In the present study, high level of cholesterol and LDL decreased expression of Th1 related cytokines such as IFN- $\gamma$, TNF- $\alpha$, IL- 2 cytokines and T-bet transcription factor. T-bet is an important transcription factor of Th1 related cytokines and in differentiation of Th0 to Th1. Our results are in agreement with the report of Lei et al. [16] concerning the decrease of TNF- $\alpha$ and IL-6 in ApoE-/- hyperlipidemic mice [16].

IL-2 is required for initiation of effector functions thereby regulating T-cell-mediated immune responses and plays a critical role in the activation of immune system that can help to destruction of the cancer cells. As immunotherapy, IL-2 can use for tumor regression and was approved for metastatic renal cell carcinoma and metastatic melanoma by FDA [38]. Interferon gamma (IFN- $\gamma$ ), a cytokine secreted by activated $\mathrm{T}$ cells and natural killer cells, by regulating $\mathrm{T}$ cell responses, especially $\mathrm{Th} 1$ cells, can effects on tumor rejection $[39,40]$ while loss of IFN- $\gamma$ lead to impair antitumor $\mathrm{T}$ cell response and allow tumor cell growth [41]. Moreover, IFN- $\gamma$ can inhibit the production of angiogenic factors by tumor cells, promote the production of antiangiogenic factors by host stroma cells in vivo and result in inhibit the tumor-induced angiogenesis [42]. Th1 cells effect in the upgrade and conservation of anti-tumor cytotoxic CD8+ $\mathrm{T}$ lymphocytes responses and also employees several cells of innate and adaptive immunity to tumor sites and stimulate their activation by secretion of IFN- $\gamma$ [43]. Also, IFN- $\gamma$ enhance immunogenicity of tumor cells via up-regulation of the antigen-presenting MHC molecules membrane expression on the tumor cells and makes them more susceptible to immune recognition and destruction [44].

This cytokine inhibited proliferation of tumor cells by up regulation of p21 and p27 molecules to arrest the cell cycle $[45,46]$. TNF- $\alpha$ can initiate diverse forms of programmed cell death including apoptosis and necroptosis in tumor cells [47]. Up regulation of TNF- $\alpha$ can led to killing tumor cells in in vitro systems and in animal models [48]. Collectively, Th1 related cytokines such as IL-2, IFN- $\gamma$ and TNF- $\alpha$ was shown to use its potent anti-tumor effect via modulating immune cells, tumor cells and/or non-immune stromal cells in tumor microenvironment. On the other hand, in the present study, high level of cholesterol and LDL decreased expression of IFN- $\gamma$, TNF- $\alpha$, IL- 2 cytokines and T-bet transcription factor that might inhibit innate immune responses and can increase the risk of cancer. This effect of hyperlipidemia is perhaps caused by changes of the cholesterol concentration in the $\mathrm{T}$ cell membrane resulting in interference of the TCR signaling cascade as shown by in vitro studies earlier [49]. These findings raise the possibility that the suppressive effects of LDL-cholesterol on the immune system might facilitate the survival of cancer cells in body.

\section{References}

1. Nelson RH (2013) Hyperlipidemia as a risk factor for cardiovascular disease. Primary Care: Clinics in Office Practice 40(1): 195-211.

2. Shattat GF (2015) A review article on hyperlipidemia: types, treatments and new drug targets. Biomedical and Pharmacology Journal 7(2): 399409.

3. Tuttolomondo A, Di Raimondo D, Pecoraro R, Arnao V, Pinto A, et al. (2012) Atherosclerosis as an inflammatory disease. Current pharmaceutical design 18(29): 4266-4288.

4. Smith E, Prasad K MR, Butcher M, Dobrian A, Kolls JK, et al. (2010) Blockade of interleukin-17A results in reduced atherosclerosis in apolipoprotein E-deficient mice. Circulation 121(15): 1746-7155.

5. Tedgui A, Mallat Z (2006) Cytokines in atherosclerosis: pathogenic and regulatory pathways. Physiological reviews 86(2): 515-581.

6. Parrott MD, Greenwood CE (2007) Dietary influences on cognitive function with aging. Annals of the New York Academy of Sciences 1114: 389-397.

7. Chavarro JE, Rich Edwards JW, Rosner BA, Willett WC (2007) Dietary fatty acid intakes and the risk of ovulatory infertility. The American journal of clinical nutrition 85(1): 231-237.

8. Missmer SA, Chavarro JE, Malspeis S, Bertone Johnson ER, Hornstein MD, et al. (2010) A prospective study of dietary fat consumption and endometriosis risk. Human Reproduction 25(6): 1528-1535.

9. Schwarz S, Leweling H (2005) Multiple sclerosis and nutrition. Multiple Sclerosis Journal 11(1): 24-32.

10. Willert W, Mac Mahon B (1984) Diet and cancer-an overview. N Engl J Med 310: 633-638.

11. Hiatt RA, Friedman GD, Bawol RD, Ury HK (1982) Breast Cancer and Serum Cholesterol. Journal of the National Cancer Institute 68(6): 885889.

12. Gaziano JM, Hennekens CH (1995) Dietary fat and risk of prostate cancer. Oxford University Press.

13. Howe GR, Aronson KJ, Benito E, Castelleto R, Cornée J, et al. (1997) The relationship between dietary fat intake and risk of colorectal cancer: evidence from the combined analysis of 13 case-control studies. Cancer Causes and Control 8(2): 215-228.

14.Zhang S, Hunter DJ, Rosner BA, Colditz GA, Fuchs CS, Speizer FE, et al. (1999) Dietary fat and protein in relation to risk of non-Hodgkin's lymphoma among women. Journal of the National Cancer Institute 91(20): 1751-1788.

15. Font Burgada J, Sun B, Karin M (2016) Obesity and cancer: the oil that feeds the flame. Cell metabolism 23(1): 48-62.

16. Lei L, Li H, Yan F, Xiao Y (2013) Hyperlipidemia impaired innate immune response to periodontal pathogen Porphyromonas gingivalis in apolipoprotein E knockout mice. Plos one 8: 71849.

17. Notarnicola M, Altomare DF, Correale M, Ruggieri E, D'Attoma B, et al. (2005) Serum lipid profile in colorectal cancer patients with and without synchronous distant metastases. Oncology 68(4): 371-374.

18. Tie G, Yan J, Khair L, Messina JA, Deng A, etal. (2017) Hypercholesterolemia increases colorectal cancer incidence by reducing production of NKT and $\gamma \delta \mathrm{T}$ cells from hematopoietic stem cells. Cancer research 77(9): 2351-2362.

19. Dansky HM, Charlton SA, Harper MM, Smith JD (1997) T and B lymphocytes play a minor role in atherosclerotic plaque formation in the apolipoprotein E-deficient mouse. Proceedings of the National Academy of Sciences 94(4): 4642-4646. 
20. Zhou X, Paulsson G, Stemme S, Hansson GK (1998) Hypercholesterolemia is associated with a T helper (Th) $1 / \mathrm{Th} 2$ switch of the autoimmune response in atherosclerotic apo E-knockout mice. Journal of Clinical Investigation 101(8): 1717-1725.

21. Robertson AK, Zhou X, Strandvik B, Hansson G (2004) Severe hypercholesterolaemia leads to strong Th2 responses to an exogenous antigen. Scandinavian journal of immunology 59(3): 285-293.

22. Zhou X, Johnston TP, Johansson D, Parini P, Funa K, et al. (2009) Hypercholesterolemia leads to elevated TGF- $\beta 1$ activity and T helper 3-dependent autoimmune responses in atherosclerotic mice. Atherosclerosis 204(2): 381-387.

23. Sako A, Kitayama J, Kaisaki S, Nagawa H (2004) Hyperlipidemia is a risk factor for lymphatic metastasis in superficial esophageal carcinoma. Cancer letters 208(1): 43-49.

24. Sherwin RW, Wentworth DN, Cutler JA, Hulley SB, Kuller LH, et al. (1987) Serum cholesterol levels and cancer mortality in 361662 men screened for the multiple risk factor intervention trial. Jama 257: 943-948.

25. Nomura AM, Stemmermann GN, Chyou PH (1991) Prospective study of serum cholesterol levels and large-bowel cancer. JNCI: Journal of the National Cancer Institute 83(19): 1403-1407.

26. Organization WH (2002) The world health report 2002: reducing risks, promoting healthy life: World Health Organization.

27. Lee Y, Kim J, An J, Lee S, Lee H, et al. (2017) Restoration of Declined Immune Responses and Hyperlipidemia by Rubus occidenalis in DietInduced Obese Mice. Biomolecules \& therapeutics 25(2): 140-148.

28. Vonk AG, Bont ND, Netea MG, Demacker PN, Van Der Meer JW, et al. (2004) Apolipoprotein-E-deficient mice exhibit an increased susceptibility to disseminated candidiasis. Medical mycology 42(4): 341-348.

29. Roselaar SE, Daugherty A (1998) Apolipoprotein E-deficient mice have impaired innate immune responses to Listeria monocytogenes in vivo. Journal of lipid research 39(9): 1740-1743.

30. De Bont N, Netea M, Demacker P, Kullberg B, Van Der Meer J, et al. (2000) Apolipoprotein E-deficient mice have an impaired immune response to Klebsiella pneumoniae. European journal of clinical investigation 30 818-822.

31. Ludewig B, Jäggi M, Dumrese T, Brduscha-Riem K, Odermatt B, et al. (2001) Hypercholesterolemia exacerbates virus-induced immunopathologic liver disease via suppression of antiviral cytotoxic T cell responses. The Journal of Immunology 166(5): 3369-3376.

32. Rao LN, Ponnusamy T, Philip S, Mukhopadhyay R, Kakkar VV, et al. (2015) Hypercholesterolemia Induced Immune Response and Inflammation on Progression of Atherosclerosis in Apobtm2SgyLdlrtm1Her. J Mice Lipids 50(8): 785-797.

33. Mailer RK, Gisterå A, Polyzos KA, Ketelhuth DF, Hansson GK (2017) Hypercholesterolemia Induces Differentiation of Regulatory T Cells in the Liver. Circulation Research 120(11).

\section{ISSN: 2574-1241}

\section{DOI: $10.26717 / B J S T R .2018 .12 .002240$}

Ghasem Ahangari. Biomed J Sci \& Tech Res

This work is licensed under Creative

Commons Attribution 4.0 License

Submission Link: https://biomedres.us/submit-manuscript.php
34. Libby P, Ridker PM, Hansson GK (2011) Progress and challenges in translating the biology of atherosclerosis. Nature 473(7347): 317-325.

35. Cimato TR, Palka BA, Lang JK, Young RF (2013) LDL cholesterol modulates human CD34+ HSPCs through effects on proliferation and the IL-17 G-CSF axis. Plos one 8: e73861.

36. Yuan J, Bagley J, Iacomini J (2015) Hyperlipidemia Promotes Anti-Donor Th17 Responses That Accelerate Allograft Rejection. American Journal of Transplantation 15(9): 2336-2345

37. Proto JD, Doran AC, Subramanian M, Wang H, Zhang M, et al. (2018) Hypercholesterolemia induces $\mathrm{T}$ cell expansion in humanized immune mice. The Journal of clinical investigation 128(6): 2370-2375.

38. Jiang T, Zhou C, Ren S (2016) Role of IL-2 in cancer immunotherapy. Oncoimmunology 5(6).

39. Dunn GP, Koebel CM, Schreiber RD (2005) Interferons, immunity and cancer immunoediting. Nature Reviews Immunology 6(11): 836-848.

40. Szabo SI, Sullivan BM, Peng SL, Glimcher LH (2003) Molecular mechanisms regulating Th1 immune responses. Annual review of immunology 21: 713-758.

41. Ikeda H, Old LJ, Schreiber RD (2002) The roles of IFN $\gamma$ in protection against tumor development and cancer immunoediting. Cytokine \& growth factor reviews 13(2): 95-109.

42. Hayakawa Y, Takeda K, Yagita H, Smyth MJ, Van Kaer L, et al. (2002) IFN- $\gamma$-mediated inhibition of tumor angiogenesis by natural killer T-cell ligand, $\alpha$-galactosylceramide. Blood 100(5): 1728-1733.

43. Kennedy R, Celis E (2008) Multiple roles for CD4+ T cells in anti-tumor immune responses. Immunological reviews 222: 129-44.

44. Vigneron N (2015) Human tumor antigens and cancer immunotherapy. BioMed research international.

45. Chawla Sarkar M, Lindner D, Liu YF, Williams B, Sen G, et al. (2003) Apoptosis and interferons: role of interferon-stimulated genes as mediators of apoptosis. Apoptosis 8(3): 237-249.

46. Chin YE, Kitagawa M, Su WCS, You ZH, Iwamoto Y, et al. (1996) Cell growth arrest and induction of cyclin-dependent kinase inhibitor p21WAF1/CIP1 mediated by STAT1. Science 272(5262): 719-22.

47. Zheng L, Bidere N, Staudt D, Cubre A, Orenstein J, et al. (2006) Competitive control of independent programs of tumor necrosis factor receptor-induced cell death by TRADD and RIP1. Molecular and cellular biology 26(9): 3505-3513.

48. Waters JP, Pober JS, Bradley JR (2013) Tumour necrosis factor and cancer. The Journal of pathology 230(3): 241-248.

49. Stulnig TM, Berger M, Sigmund T, Stockinger H, Hořejší V, et al. (1997) Signal transduction via glycosyl phosphatidylinositol-anchored proteins in $\mathrm{T}$ cells is inhibited by lowering cellular cholesterol. Journal of Biological Chemistry 272: 19242-19247.

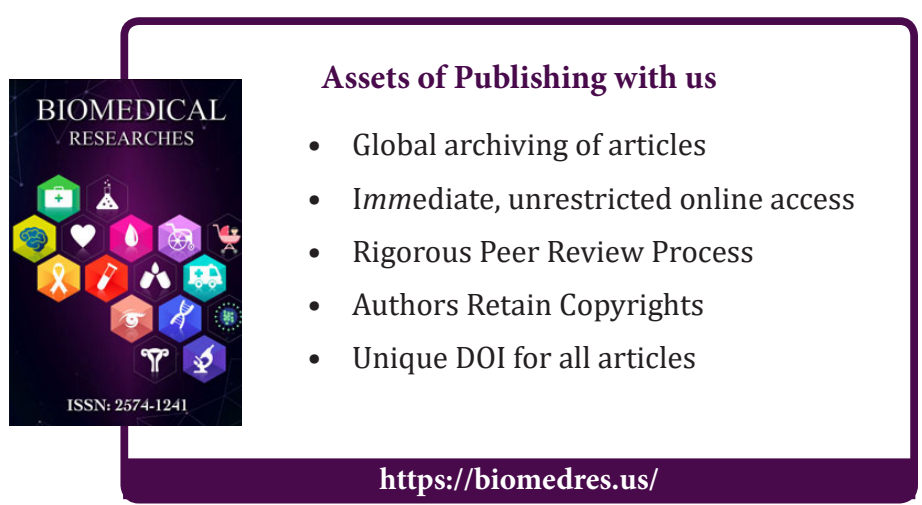

Cite this article: Zeinab E, Pegah B, Mahmoud A, Ghasem A. Effect of Hyperlipidemia on Cell Mediated Immunity; Could it be as Predisposing Factor of Cancer Risk. Biomed J Sci \& Tech Res 12(3)-2018. BJSTR. MS.ID.002240. DOI: 10.26717/ BJSTR.2018.12.002240. 